\title{
Enterprise Quality Cost Research Based on Activity-based Costing
}

\author{
Chun-Li Li, Hu-Sheng Lu \\ College of Economic and Management of Inner Mongolia University of Science and \\ Technology, Baotou, Inner Mongolia 014010 \\ lichunli2601@163.com
}

Keywords: Quality cost, Activity-based costing, Activity quality cost, Quality activity.

\begin{abstract}
The application of activity-based costing in the accounting of quality cost has solved the problems that exist in the traditional quality cost accounting; the enterprise of rare earth is used as the research object in the paper and the activity quality cost model is constructed, the quality costs of the enterprise are collected and allocated; meanwhile the quality activity is analyzed and the suggestions of improvement are presented so as to improve quality interest and reach the purpose of cost reduction and benefit increase for the enterprise.

Along with the continuous development of human society, quality has attracted much attention as a permanent topic. Quality issue is not only related to the interest of vast consumers, but it also becomes a strategic problem for the existence and development of the enterprise; meanwhile the accounting of quality cost has become the basis for the management level to manage and decide. The single cost driver is adopted in the traditional quality cost accounting to perform cost distribution, which can't satisfy the requirements of quality cost management; however, the activity-base costing can perform accurate accounting on the quality cost and provide correct information of quality cost, meanwhile it can also conduct evaluation on various conditions of product quality cost so as to make management personnel specially perform quality cost control.
\end{abstract}

\section{Literature review}

\section{Research conditions of quality cost}

Wan Shouyi and other researchers (2010) presented the approach of quality cost optimization at the aspect of quality cost management and optimized the quality cost by this so as to reduce the quality cost and obviously improve economic benefit 1 . Through researching the changing characteristics of quality cost at various stages of the product's life cycle, Liu Weidong (2011) presented optimization design principles that the product introduction period shall be shortened as possible, the quality management requirements of zero defect at the period of product growth shall be promoted and the product maturity period shall be prolonged2. Through establishing simulation model of system dynamics, Shang Shanshan and You Jianxin (2011) studied the relationship between various components of quality cost at different quality level; they certified that the correctness of grey-linear regression combination model by case study through establishing the relationship model between the quality cost and quality level by means of grey-linear regression combination model3.

Yin Meiqun and other researchers (2000) considered using the method that the quality cost was included into the accounting system and the accounting method was used to perform collection and distribution at the aspect of quality cost accounting and collection4. Hou Lan (2006) performed detailed comparison on the PAF method, process-based costing and activity-based costing and he presented its significance on the accounting and measuring of implicit quality costs5. Ren Yuejun (2008) performed discussion on the content of quality cost accounting and compared the similarities and differences as well as the relationship between the product cost and quality cost so as to perform classification on the quality costs6.

\section{Research conditions of activity-based costing}

The American scholar Stan Bers (1971) made systematic and comprehensive discussion on the relevant concepts of "activity", "costs", "accounting" and "work input and output system" at the activity costing and input-output accounting. The scholar of Harvard University Robin Cooper and Robert Kaplan (1989) presented the method of ABC and performed specific research on the current 
requirements, selection procedure, cost driver and cost pool of $\mathrm{ABC}$. In the activity-based costing, Liu Guangsheng (2011) researched how to correctly select the method of cost driver in the best selection method of cost driver. The conclusion was obtained through the establishment and solution of mathematical model and it's certified that the one cost driver won't be affected after being replaced by other series of cost driver combinations 7 .

\section{Research conditions of work quality costs}

Lin Wanxiang (2001) presented the concept of activity-quality based costing management, discussed and analyzed the formation and application of activity quality cost so as to put forward three steps of activity-based cost management, including the analysis on quality activity and cost driver and the establishment of performance evaluation system8. Liu Zhiying (2009) presented 4 activity centers that's related to enterprise and quality cost management, including prevention center, evaluation center, internal and external fault center and unified coordination center. Ge Huanzhong (2010) presented that the division of activity centers shall be appropriate, the selection of critical control points shall be accurate and the allocation of sources shall be reasonable. Yu Dehui and other researchers (2010) presented the thought of the combination between the activity-based costing and quality cost management and illustrated the steps of using activity-based costing to perform quality cost accounting and management procedures 9 .

\section{Construction of activity quality cost model}

The principle of activity-based costing is "products consume activities and activities consume resources"; therefore, produce quality cost is the sum of various quality activity costs, but various quality activity costs is the product of the resources quantity consumed in the activity and the price of corresponding resource prices.

It's assumed that the enterprise produces $\mathrm{m}$ kinds of products, there are totally $\mathrm{n}$ quality activities and s kinds of resources are consumed. Meanwhile it's assumed that $\mathrm{C}$ is the product quality cost, Qij is the quantity that the jth quality activity that's consumed by the ith kind of product; Qjq is the quantity that the qth kind of resource that's consumed by the jth quality activity; Pq is the unit price of the qth kind of resource; Ci represents the quality cost that's needed by the ith kind of product. Under the activity-based costing, the product quality cost can be calculated according to the formula 2.1:

$$
C_{i}=\sum_{j=1}^{n} Q_{\mathrm{ij}} \times\left(\sum_{q=1}^{s} R_{j q} \times P_{q}\right) \quad(\mathrm{i}=1,2, \ldots \mathrm{m} ; \mathrm{j}=1,2, \ldots . \mathrm{n} ; \mathrm{q}=1,2, \ldots . \mathrm{s})
$$

The model is represented by the matrix as follows:

$$
\left[\begin{array}{c}
C_{1} \\
C_{2} \\
\ldots \\
C_{m}
\end{array}\right]=\left[\begin{array}{cccc}
Q_{11} & Q_{12} & \ldots & Q_{1 m} \\
Q_{21} & Q_{22} & \ldots & Q_{2 m} \\
\ldots & \ldots & \ldots & \ldots \\
Q_{m 1} & Q_{m 2} & \ldots & Q_{m m}
\end{array}\right]\left[\begin{array}{cccc}
R_{11} & R_{12} & \ldots & R_{1 n} \\
R_{21} & R_{22} & \ldots & R_{2 n} \\
\ldots & \ldots & \ldots & \ldots \\
R_{m 1} & R_{m 2} & \ldots & R_{m n}
\end{array}\right]\left[\begin{array}{c}
P_{1} \\
P_{2} \\
\ldots \\
P_{m}
\end{array}\right]
$$

Thereinto, $\mathrm{Q}$ is the activity quantity matrix that's consumed by the product, $\mathrm{R}$ is the resource quantity matrix that's consumed by the activity and $\mathrm{P}$ is the unit price matrix of the resource. There are lots of variables involved in the above model, it's very inconvenient to use this model to calculate the quality cost. Therefore, the concepts of activity cost pool and cost driver rate are applied to improve the model: it's assumed that the enterprise totally has $\mathrm{m}$ kinds of products and $\mathrm{n}$ activity cost pools are divided. cj is the resource cost that's consumed by the jth activity cost pool; dij is the cost driver quantity of the ith kind of product at the jth cost pool for per unit.

$\mathrm{dj}$ is the total quantity of the cost driver for the jth cost pool; rij is the cost driver rate of the ith kind of product at the jth cost pool; $\mathrm{Ci}$ represents the quality cost that's needed by the ith kind of product, refer to the formula 2.3 and 2.4 . 


$$
\begin{aligned}
& r_{i j}=d_{i j} \div d_{j}(i=1,2, \ldots m ; j=1,2, \ldots n) \sum_{i=1}^{m} r_{i j}=1 \\
& C_{i}=\sum_{j=1}^{n} c_{j} \times r_{i j}(i=1,2, \ldots m ; j=1,2, \ldots, n)
\end{aligned}
$$

At the activity cost accounting system, the costs of various activity cost pools can be obtained from the daily job logging of the accounting and the cost driver rates of various cost pools can also be calculated according to the known data; therefore, the following model can be used to calculate the quality cost of the activity.

$$
\left[\begin{array}{l}
C_{1} \\
C_{2} \\
\ldots \\
C_{m}
\end{array}\right]=\left[\begin{array}{cccc}
r_{11} & r_{12} & \ldots & r_{1 m} \\
r_{21} & r_{22} & \ldots & r_{2 m} \\
\ldots & \ldots & \ldots & \ldots \\
r_{m 1} & r_{m 2} & \ldots & r_{m m}
\end{array}\right]\left[\begin{array}{c}
c_{1} \\
c_{2} \\
\ldots \\
c_{n}
\end{array}\right]
$$

We can know that the new activity costing model has less variables by comparing the formula 2.2 and 2.5, the calculation process is easy and the calculation thought is clear. Therefore, the improved activity costing mathematical model shall be adopted to calculate the quality cost.

\section{Empirical analysis}

The HF RE enterprise is selected as the example to perform analysis, which is mainly specialized in the purification, processing and smelting of rare earth ore concentrate. It currently has the production lines of rare earth ore concentrate roasting rotary kiln, mix rare earth carbonates, rare earth extraction separation and oxidizing roasting pushed slab kiln; it has various levels of rough machining and deep processing are involved in rare earth. The main products include SmEuGd's rare earth liquid, lanthanum oxide, cerium oxide, praseodymium-neodymium oxide and lanthanum-cerium and other REOs, the purity of products can satisfy the requirements of various specifications.

\section{Division of quality activity}

The quality activity is divided into four kinds according to the PAF, which are prevention activity, identification activity, internal and external loss activity. Thereinto, the internal loss activity and external loss activity belong to the loss activity. Prevention activity includes the inspection and preparation activity before the machine operation, the quality certification activity and various activities for improving quality or preventing loss; the identification activity includes the detection and identification activities of product's various indexes, identification activity of raw materials and workshop inspection activities, etc; internal loss activity includes the internal correction activity and loss due to reworking of rare earth products; external loss activity includes the customer complaint and compensation that's handled by the customer service center.

\section{Collection of activity quality costs}

(1) The consumed resources are analyzed. The resources are consumed according to activity-based costing principle; the consumed resource can be traced from the activity so as to confirm the types of consumed resources. Through classification the consumed labor expenses, depreciation expenses of fixed assets, electric charge and fuel cost.

(2) The resource driver is analyzed. The resource driver means the methods and reasons of consuming various corresponding resources at various activities, which is the standard for collecting resources into the activity center and each kind of resource is corresponding to different resource driver. Corresponding to the consumed resources, the corresponding resource drivers of labor expenses, depreciation expenses of fixed assets, electric charge, fuel cost are man-hour, machine-hour, electricity consumption and machine-hour. 
(3) The activity cost is collected according to resource driver. The consumed resources are collected into various activities according to the resource driver so as to obtain the cost of each activity.

Tab. 3.1 Resource consumption and resource driver

\begin{tabular}{l|l|l|l}
\hline Resource name & Resource cost & Resource driver & Total quantity of resource driver \\
\hline \multirow{2}{*}{ Labor expenses } & \multirow{2}{*}{77969.23} & Man-hour & 6547.2 \\
\cline { 3 - 4 } $\begin{array}{l}\text { Depreciation expenses of } \\
\text { fixed assets }\end{array}$ & \multirow{2}{*}{3042.62} & Cost driver rate & 11.91 \\
\hline \multirow{2}{*}{ Electric charge } & & Machine-hour & 818.4 \\
\cline { 3 - 4 } & \multirow{2}{*}{56769.37} & Cost driver rate & 3.72 \\
\cline { 3 - 4 } Fuel cost & & Electricity consumption & 113556.2 \\
\cline { 3 - 4 } & \multirow{2}{*}{71584.77} & Cost driver rate & 0.49 \\
\cline { 3 - 4 } & & Machine-hour & 838.6 \\
\hline
\end{tabular}

\section{Allocation of activity quality cost}

According to the part of "product consumption activity" in the principle of activity-based costing, the costs of various activities obtained from the calculation of the first part are allocated to the corresponding products according to the activity driver, refer to table 3.2.

The classification prevention cost, identification cost, internal loss cost and external loss cost of the quality cost activities allocated to the corresponding products are summarized so as to obtain the quality cost of each product, see table 3.3.

Tab. 3.2 Result analysis table of activity cost allocation

\begin{tabular}{l|l|l|l|l|l|l}
\hline Activity name & $\begin{array}{l}\text { Undistribu } \\
\text { ted amount }\end{array}$ & $\begin{array}{l}\text { SmEuGd's } \\
\text { rare earth } \\
\text { liquid }\end{array}$ & $\begin{array}{l}\text { Lanthanu } \\
\text { m oxide }\end{array}$ & $\begin{array}{l}\text { Cerium } \\
\text { oxide }\end{array}$ & $\begin{array}{l}\text { Praseodymiu } \\
\text { m-neodymiu } \\
\text { m oxide }\end{array}$ & $\begin{array}{l}\text { Lanthanum- } \\
\text { cerium } \\
\text { oxide }\end{array}$ \\
\hline $\begin{array}{l}\text { Extraction and } \\
\text { preparation slotting } \\
\text { activity }\end{array}$ & 14392.8532 & 1410.4992 & 3108.8563 & 6491.177 & 2259.6783 & 1122.6424 \\
\hline $\begin{array}{l}\text { Launch and } \\
\text { preparation stage } \\
\text { activity of slot }\end{array}$ & 12324.3538 & 1207.7868 & 2662.0605 & 5558.2835 & 1934.9231 & 961.2999 \\
\hline $\begin{array}{l}\text { Flow calibration } \\
\text { activity }\end{array}$ & 4645.6311 & 473.8547 & 1026.685 & 2067.3059 & 706.1362 & 371.6504 \\
\hline $\begin{array}{l}\text { Inspection tour } \\
\text { activity of slot }\end{array}$ & 13910.9366 & 1363.2718 & 3004.7622 & 6273.8324 & 2184.017 & 1085.0532 \\
\hline $\begin{array}{l}\text { Slot monitoring } \\
\text { activity }\end{array}$ & 12458.2183 & 1270.7387 & 2740.8084 & 5593.7398 & 1868.7328 & 984.1997 \\
\hline $\begin{array}{l}\text { Flow adjustment } \\
\text { activity }\end{array}$ & 5543.7569 & 609.8136 & 1180.8203 & 2511.322 & 831.5637 & 410.2384 \\
\hline $\begin{array}{l}\text { Activity of slot stop } \\
\text { and settlement stage }\end{array}$ & 5959.0916 & 583.9911 & 1287.1639 & 2687.5508 & 935.5775 & 464.8094 \\
\hline $\begin{array}{l}\text { Activity of acid } \\
\text { solution callback and } \\
\text { preparation stage }\end{array}$ & 5680.0535 & 556.6451 & 1226.8916 & 2561.7042 & 891.7689 & 443.0437 \\
\hline $\begin{array}{l}\text { Inspection activity of } \\
\text { acid solution callback }\end{array}$ & 19340.904 & 1856.7263 & 4216.3176 & 8703.4068 & 3075.204 & 1489.2493 \\
\hline $\begin{array}{l}\text { Stirring activity of } \\
\text { acid solution callback }\end{array}$ & 11715.5214 & 1148.1206 & 2530.5522 & 5283.7004 & 1839.3364 & 913.8107 \\
\hline $\begin{array}{l}\text { Activity at settlement } \\
\text { stage of acid solution } \\
\text { callback }\end{array}$ & 4744.7356 & 464.9843 & 1024.8634 & 2139.8762 & 744.9233 & 370.0895 \\
\hline \begin{tabular}{l} 
Total \\
\hline
\end{tabular} & 10946.4322 & 24009.7814 & 49871.899 & 17271.8612 & 8616.0866 \\
\hline
\end{tabular}


Tab. 3.3 Summary sheet of product quality cost

\begin{tabular}{l|l|l|l|l|l|l}
\hline Item & $\begin{array}{l}\text { SmEuGd's } \\
\text { rare earth } \\
\text { liquid }\end{array}$ & $\begin{array}{l}\text { Lanthanu } \\
\text { m oxide }\end{array}$ & $\begin{array}{l}\text { Cerium } \\
\text { oxide }\end{array}$ & $\begin{array}{l}\text { Praseodymium- } \\
\text { neodymium } \\
\text { oxide }\end{array}$ & $\begin{array}{l}\text { Lanthanu } \\
\text { m-cerium } \\
\text { oxide }\end{array}$ & total \\
\hline $\begin{array}{l}\text { Prevention } \\
\text { cost }\end{array}$ & 33841.775 & 74416.097 & 155006.56 & 53638.351 & 26892.798 & 343795.58 \\
\hline $\begin{array}{l}\text { Identifica- } \\
\text { tion cost }\end{array}$ & 25433.307 & 54851.665 & 113890.13 & 38271.644 & 18365.852 & 250812.6 \\
\hline $\begin{array}{l}\text { Internal } \\
\text { loss cost }\end{array}$ & 20486.699 & 45234.059 & 93519.362 & 32459.823 & 16326.177 & 208026.12 \\
\hline $\begin{array}{l}\text { External } \\
\text { loss cost }\end{array}$ & 1240.6493 & 2828.3167 & 5770.4845 & 1967.8362 & 976.4128 & 12783.7 \\
\hline
\end{tabular}

\section{Analysis and improvement of the quality activity}

The production process is divided into activities by applying activity-based costing according to the principle of activity quality cost model, the quality cost is expressed at quality activity, the analysis on quality cost is also analyzed from the perspective of quality activity; therefore, the management on quality cost is also expressed at the management of quality activity.

(1) The quality activity is divided into prevention activity, identification activity and loss activity according to PAF, the cost at the identification activity of HF rare earth enterprise is the one of relative stability, but the cost of loss activity is mostly decided by the prevention activity if it can produce function, only the prevention activity is controllable.

(2) We can also see from the results of practical collection and allocation that the prevention cost occupies $42.16 \%$ of the whole quality cost. The management on prevention cost also becomes important due to its absolute advantage in the ratio. The purpose of calculating the product quality cost is to improve quality cost and enhance quality interest so as to reach the target of cost reduction and benefit increase for the enterprise; the management on prevention cost also decides the effect of managing the quality cost to a large extent.

\section{Conclusion}

The accounting of quality cost is a complicated work, the application of traditional statistical accounting method can't obtain accurate data of quality cost, but the use of activity quality cost can better solve this problem.

The activity-based costing is adopted for the enterprise of rare earth in this paper, the whole production process is refined into activities, the corresponding cost of each activity is obtained at the part of quality cost collection and the quantity of cost consumption for each activity can be intuitionally found. The quality costs of corresponding products are finally obtained through the collection and allocation of the quality cost, which fills the gap that enterprises can't correctly obtain the product quality cost so as to lay a solid foundation for further quality management.

\section{Acknowledgement}

This paper is subsidized by the Inner Mongolia Natural Science Funds (2012MS1009) and National Science Foundation of China (71162027).

\section{References}

[1] Wan Shouyi, Li Chuanyu. Discussion on the Quality Cost Optimization under the Idea of Modern Quality Cost (J). Friends of Accounting, 2010 (4): 7-10.

[2] Liu Weidong, Ying Jing. Quality Cost Model and Analysis Based on Product's Life Cycle (J). Management Review, 2011,23(2):117-121. 
[3] Shang Shanshan, You Jianxin. Relationship Research and Model Establishment of Various Elements for Quality Cost (J). Management Review. 2011,23(9):160-166.

[4] Yin Meiqun, Luo Xiaoguang. Collection and Accounting of Quality Costs (J). Value Engineering, 2000(6):40-42.

[5] Hou Lan. Comparative Research on Quality Cost Measurement Method (J). World Standardization and Quality Management, 2006(1):33-34.

[6] Ren Yuejun. Discussion on Quality Cost Accounting (J). Journal of Dongbei University of Finance and Economics, 2008(4):25-28.

[7] Liu Guangsheng, Ding Ling. The Best Selection Method of Cost Driver in Activity-based Costing (J). Monthly of Finance and Accounting 2011(10):55-56.

[8]Lin Wanxiang. Discussion on the Formation and Application of Activity Quality Cost Management (J). Monthly of Finance and Accounting, 2001(2):4-5.

[9] Yu Dehui, Wan Limei. Application of Activity-based Costing in Quality Cost Management (J). Communication of Finance and Accounting, 2010(9):137-138. 